\title{
Análise da variação terminológica denominativa em textos jurídicos: o caso do termo petição inicial
}

\author{
Analysis of terminological \\ denominative variation in legal \\ texts: the case of petição inicial \\ (complaint/initial pleading)
}

\section{Amanda Henrique Pereira* Odair Luiz Nadin**}

Resumo: Temos por objetivo, no presente texto, apresentar uma análise de ocorrência de variação denominativa do termo petição inicial em textos jurídicos. A detecção de possíveis variantes para o termo em questão motivou-nos a desenvolver a presente análise. Visamos, portanto, identificar, a partir de uma lista de 34 possíveis variantes denominativas para o termo petição inicial, quais desses são utilizados como variantes da unidade terminológica em questão. Para tanto, observamos 20 peças jurídicas. Para realizarmos nossa análise, pautamo-nos, principalmente, em Freixa (2002; 2006; 2014) e Cabré (1999). Tendo isso, por meio da perspectiva da Teoria Comunicativa da Terminologia, identificamos variantes denominativas e verificamos as ocorrências delas no corpus.

* Doutoranda em Linguística e Língua Portuguesa pela Universidade Estadual Paulista - Júlio Mesquita Filho (UNESP/FCL-Ar). E-mail: ahp.unesp@gmail.com.

** Professor Associado (R.D.I.D.P.) do Departamento de Letras Modernas da Faculdade de Ciências e Letras da Universidade Estadual Paulista Júlio de Mesquita Filho - campus de Araraquara. Email: odair.nadin@unesp.br 
Palavras-chave: Terminologia; Variação terminológica; Terminologia do Direito.

Abstract:This article aims to present an analysis about the occurrence of denominative variation of the term petição inicial (complaint/initial pleading) in legal texts. Detecting possible variants for this term motivated us to develop this research. From a list of 34 denominative variants for term petição inicial, we verified which of them are used as variants for the term in question. For this purpose, we observed 20 samples of legal texts. In order to develop this research, we considered mainly the assumptions by Freixa (2002; 2006; 2014) and Cabré (1999). Therefore, based on the Communicative Theory of Terminology, we identified the possible denominative variants for the term and verified how the variation happens in the samples.

Keywords: Terminology; Terminological variation; Legal Terminology.

\section{Introdução}

Temos, no presente artigo, o objetivo de analisar a ocorrência de variação terminológica denominativa do termo que designa os textos iniciais de um processo jurídico, a petição inicial. Analisamos como são denominadas as petições iniciais a partir de três gêneros textuais: a sentença, a impugnação e a contestação. $\mathrm{O}$ enfoque na variação denominativa se justifica a partir da detecção de 34 possíveis termos ${ }^{1}$ em uso para fazer menção ao texto inicial de um processo jurídico. 0 grande número de possibilidades de uso nos chamou a atenção, motivando-nos, assim, a verificar como esses usos ocorrem nesses textos.

Partimos do pressuposto compartilhado por Freixa (2014), e outros autores que dedicam-se à Terminologia (CABRÉ 1999, Nadin 2013, Pereira 2018), que a variação terminológica não é uma anormalidade, tampouco um fator negativo na língua, mas um processo natural e que pode ocorrer por diversas motivações no âmbito das comunicações especializadas. As causas da variação denominativa nesses gêneros discursivos jurídicos e como ela ocorre

\footnotetext{
${ }^{1}$ Os termos analisados encontram-se na seção Metodologia. 
impulsionam nossa investigação. Julgamos que estudar a variação terminológica corrobora a compreensão geral de como a língua funciona em domínios especializados.

Por isso, por meio de uma análise descritiva, investigamos a variação denominativa. Para tanto, apoiamo-nos em pressupostos alçados pela Teoria Comunicativa da Terminologia (TCT), conforme Cabré (1999), pois a TCT assume, como outras teorias de base comunicativa e/ou variacionista, o princípio de que o termo é um dos objetos de estudo da Terminologia e que admite a variação ou qualquer outra questão relativa ao uso de uma língua natural. Pautamo-nos, também, em Nadin (2013) e Freixa (2006, 2014); pois esses autores se dedicam ao estudo da variação denominativa, apontando algumas possíveis causas para esse fenômeno. Além desses, baseamo-nos em Pereira (2018), que abordou em suas pesquisas a problemática da variação terminológica no âmbito jurídico.

\section{Terminologia e variação denominativa}

Nesta seção, dedicamo-nos a recuperar pressupostos teóricos que embasam nossa investigação. Em um primeiro momento, discorremos acerca da variação denominativa retomando as pesquisas de Cabré (1999), Freixa (2002, 2006, 2014), Nadin (2013) e Pereira (2018). Esses autores debruçaram-se sobre a Terminologia e sobre a variação, auxiliando-nos a identificar e compreender como ela ocorre nos usos das línguas naturais em contextos especializados.

A Terminologia, nos dias atuais, constitui-se como uma ciência consolidada, com objeto de pesquisa e objetivos estabelecidos. Desde meados do século $X X$, quando despontavam as primeiras pesquisas que se ocupavam da Terminologia, diversas transformações ocorreram nesse domínio científico. Nesse percurso, passou-se a considerar a língua em uso na comunicação especializada como parte da língua e, portanto, como algo suscetível aos fenômenos e transformações que advêm de seu uso. Nas correntes clássicas da Terminologia (tais como a Teoria Geral da Terminologia, a Teoria de Terminologia, da escola checoslovaca e também os pressupostos da escola russa 
de Terminologia (BARROS 2004), havia grande interesse em difundir a ciência; por isso, o enfoque das teorias clássicas não era a língua em uso, mas criar, por meio da Terminologia, um ambiente controlado para a língua, a fim de tornar a comunicação nesses âmbitos mais padronizada, estrita e precisa.

Por meio de_pesquisas que adotaram perspectivas diferentes das elegidas pela Terminologia Clássica, verificaram-se outros aspectos da língua em uso nas especialidades. Passou-se a compreender que as unidades léxicas de uma língua são, a princípio, potencialmente palavras ou termos e que é no uso que se dão as especificidades de um ou de outro (CABRÉ 1999).

A Teoria Comunicativa da Terminologia, nos anos 90, apontou novos caminhos para a Terminologia, admitindo que, a partir do momento em que a língua comunica, ela é dinâmica, ou seja, modifica-se de acordo com os objetivos de comunicação dos falantes que a utilizam. No caso das terminologias, a língua comunica o conhecimento produzido no âmbito das ciências e das técnicas.

A partir dessas visões, mudanças profundas podem ser notadas na forma com que se investigam as terminologias, principalmente, com relação à metodologia de pesquisa, pois a TCT, como teoria, está apoiada sobre o que Barros (2004: 58) denomina de tripé, que contempla faces diferentes do uso da língua em contexto de especialidade. Conforme Cabré (1999: 122-123), esse tripé é formado por três bases: (i) a primeira é a teoria do conhecimento, que verifica como está organizado o conhecimento na ciência investigada. $\mathrm{Na}$ sequência (ii) a teoria da comunicação que, como citamos, prevê o emprego das terminologias em situações comunicativas específicas e diversas. Essas, por sua vez, determinam a forma de uso da língua nesses contextos. Por último, (iii) é a teoria da linguagem; pois a autora entende que, na medida em que os termos fazem parte das línguas naturais, eles devem ser analisados como tal, considerando que seu significado se revelará no contexto de uso.

Os novos panoramas teórico-metodológicos revelaram, portanto, que as terminologias fazem parte da língua e, logo, são passíveis de transformações e influências das mais diversas naturezas, como: culturais, epistemológicas e temporais. Em função do reconhecimento desses fatores que incidem nas 
terminologias, passou-se a admitir a variação terminológica, seja ela de natureza denominativa, seja ela de caráter conceitual.

Entendemos por variação denominativa quando um dado conceito de uma dada área do conhecimento humano (técnico, científico, cultural etc.) é denominado por diferentes termos. Dito de outro modo, diferentes unidades léxicas de uma língua natural são usadas em contextos de comunicação especializada para denominar um mesmo conceito. Ao contrário, quando uma mesma unidade léxica é usada para denominar diferentes conceitos em uma mesma área do conhecimento, há um caso de variação conceitual ${ }^{2}$.

0 entendimento, portanto, de que a terminologia faz parte da língua natural e é no uso em contextos especializados que se identifica uma unidade léxica como um termo foi fundamental para a mudança de olhares teóricos e metodológicos. Dentre as teorias que possuem uma visão mais variacionista e comunicativa dos usos da língua na comunicação especializada, destaca-se a TCT (CABRÉ 1999), cujos princípios teórico-metodológicos embasam nossas discussões neste artigo.

Todo processo de comunicação comporta, inerentemente, variação, manifestada em formas alternativas de denominação de um mesmo conceito (sinonímia) ou no surgimento significativo de uma mesma forma (polissemia). Esse princípio é universal para as unidades terminológicas, muito embora ocorra em diferentes níveis de acordo com as condições comunicativas de cada contexto. (CABRÉ 1999: 85, tradução nossa $)^{3}$

Por conta desses fatores, a TCT foi considerada um marco nos estudos terminológicos, pois seus pressupostos acerca da natureza do termo preveem que ele se constitui como uma unidade de estrutura multifacetada, dotada de forma e conteúdo e que pode ser influenciada sob aspectos "cognitivos, linguísticos e sociofuncionais" (CABRÉ 1999: 133).

\footnotetext{
${ }^{2}$ Não trataremos desse tipo de variação no presente artigo.

3 Todo proceso de comunicación comporta inherentemente variación, explicitada en formas alternativas de denominación del mismo concepto (sinonimia) o en apertura significativa de una misma forma (polisemia). Este principio es universal para las unidades terminológicas, si bien admite diferentes grados según las condiciones de cada tipo de condición comunicativa. (CABRÉ 1999: 85)
} 
No que diz respeito à variação terminológica, Freixa (2014) chama-nos a atenção para um fato que merece ser sublinhado. De acordo com a autora, a variação terminológica passou de um fenômeno extraordinário (até indesejado) a algo natural, que ocorre em função do caráter comunicacional da língua. A pesquisadora ainda pontua que há razões para que a variação ocorra. Tais razões podem ser demonstradas empiricamente por meio de estudos que visam compreender melhor como se dá a variação nas terminologias.

Adentrando um pouco mais no terreno da variação denominativa, nosso principal enfoque, faz-se necessário especificar o que entendemos por sinônimo e variante; pois esses conceitos dão suporte às nossas análises. Sendo assim, adotamos o mesmo ponto de vista postulado por Freixa (2014) a respeito dos conceitos em tela. Segundo a autora, o termo variação denominativa é capaz de abarcar tanto os sinônimos quanto as variantes, pois os limites entre esses dois acontecimentos linguísticos são frágeis. Além disso, Freixa (2014) justifica seu ponto de vista recuperando o fato de que, pela perspectiva variacionista, são considerados casos de variação todos aqueles em que duas ou mais formas linguísticas designam um mesmo conceito. Essas formas podem ser diferentes em termos morfológicos, lexicais ou apenas em termos gráficos. Independentemente do que caracteriza a diferença entre essas formas, todas se constituem como variantes. Por isso, em nossa pesquisa, consideramos sinônimos e variantes fatos linguísticos abrigados pela variação denominativa.

Dentre as causas apontadas para a variação denominativa, podemos destacar aspectos como diferenças culturais, motivações etimológicas, ideológicas e políticas. Dentre esse arcabouço de possibilidades, Freixa (2014), a partir do que havia sido anteriormente abordado em sua tese (FREIXA 2002), organizou um esquema de motivações que nos auxilia a identificar as razões para a variação denominativa.

Reproduzimos, a seguir, o quadro elaborado pela autora, que aponta essas causas:

Quadro 1 - Razões para variação denominativa

\begin{tabular}{|c|l|}
\hline Tipos & \multicolumn{1}{c|}{ Subtipos } \\
\hline 1. Causas prévias & $\begin{array}{l}\text { Redundância linguística } \\
\text { Arbitrariedade do signo }\end{array}$ \\
\hline
\end{tabular}




\begin{tabular}{|c|l|}
\hline & Possibilidades de variação da língua \\
\hline 2. Causas dialetais & $\begin{array}{l}\text { Variação geográfica } \\
\text { Variação cronológica } \\
\text { Variação ocial }\end{array}$ \\
\hline 3. Causas funcionais & $\begin{array}{l}\text { Adequação ao nível da língua } \\
\text { Adequação ao nível de especialidade }\end{array}$ \\
\hline 4. Causas discursivas & $\begin{array}{l}\text { Evitar a repetição } \\
\text { Economia linguística } \\
\text { Criatividade, ênfase e expressividade }\end{array}$ \\
\hline 5. Causas interlinguísticas & $\begin{array}{l}\text { Convivência do termo "local” com o } \\
\text { "empréstimo" propostas alternativas } \\
\text { Diversidade de propos }\end{array}$ \\
\hline 6. Causas cognitivas & $\begin{array}{l}\text { Imprecisão conceitual } \\
\text { Distanciamento ideológico } \\
\text { Diferentes conceptualizações }\end{array}$ \\
\hline
\end{tabular}

Fonte: Freixa (2014: 317, tradução nossa)

A tabela se divide em tipos e subtipos de causas para a variação. De acordo com Freixa (2014), o primeiro refere-se às causas prévias, que englobam três subtipos relacionados: a redundância linguística, as possibilidades de variação da língua e a arbitrariedade do signo. Os dois primeiros subtipos levam o falante da língua a criar novas palavras e a denominar os elementos de diferentes formas. Quanto ao subtipo arbitrariedade do signo, ele se refere ao fato de que, como o termo não é motivado, a não relação direta entre nome e referente seria uma possível causa para a variação.

As causas dialetais se desdobram em variação geográfica, variação cronológica e variação social. A variação geográfica aponta como causa as diferenças regionais entre os que utilizam a língua em contexto de especialidade. A depender do lugar de origem dos falantes, as denominações podem variar. Por sua vez, a variação cronológica refere-se ao fato de que diferenças temporais de usos dos termos podem motivar a variação. Um determinado termo pode dar lugar a outro em função da diferença cronológica. Por fim, a variação social refere-se a grupos sociais distintos que partilham a terminologia.

Com relação às causas funcionais, elas incluem a adequação ao nível da língua e adequação ao nível de especialidade. 0 primeiro subtipo de causa significa adequar o uso da língua ao nível de exigência que a situação comunicativa demanda, mais formal, menos formal, a depender dos objetivos 
a serem atingidos. 0 segundo subtipo está relacionado ao nível de especialidade dos textos, que poderá ser mais ou menos especializado, segundo Hoffmann (1998). Para verificar tal fator, é necessário avaliar aspectos como o gênero textual, o suporte e o teor terminológico dos textos, isto é, se há um número maior ou menor de termos específicos da área em questão.

Para as causas discursivas, Freixa (2014) aponta como subtipos evitar repetição, a economia linguística e a criatividade, ênfase e expressividade. Evitar repetição diz respeito à tendência para buscar opções nominativas para alternar no momento de construir o que se pretende comunicar, seja na forma oral ou escrita. Recorre-se a essa estratégia a fim de tornar o texto mais fluido e menos repetitivo; por esse motivo, considera-se o evitar repetição uma causa para a variação. A economia linguística está relacionada ao caráter econômico da língua. Por causa dessa característica, em situações específicas, a língua tende a reduzir o que não compromete a comunicação. Isso pode ocorrer, por exemplo, com estruturas gramaticais da língua. Nas terminologias, a redução revela-se em expressões, composições que se tornam um único termo por cumprir o objetivo comunicativo com o uso de apenas um termo. A última causa atrelada às causas discursivas diz respeito a criatividade, ênfase $e$ expressividade. Julgamos essa causa muito produtiva no ramo jurídico; pois, com o intuito de ressaltar a importância do que se diz, de tornar o discurso sofisticado e rebuscado, lança-se mão de diversos recursos de que dispõe a língua portuguesa, como, por exemplo, arcaísmos, expressões latinas, expressões complexas e a própria prolixidade característica dessa língua.

Freixa (2014) expõe, ainda, que são subtipos das causas interlinguísticas a convivência do termo local com o empréstimo e a diversidade de propostas alternativas. A convivência do termo local com o empréstimo pode ser associada às convicções políticas de um determinado local que resiste a certos empréstimos e tende a criar nomes para artefatos e teorias que possam ter origem estrangeira. Com isso, pode haver o uso alternado entre o nome estrangeiro (o empréstimo) e a terminologia local. Por sua vez, quanto ao subtipo diversidade de propostas alternativas, ele se manifesta por conta da resistência a empréstimos e termos estrangeiros. Logo, surgem diversas possiblidades alternativas que podem ser consideradas mais apropriadas por um 
determinado grupo e menos aceitas por outro. Como consequência, identificam-se diversos termos para um mesmo conceito em uma comunidade.

Por fim, acreditando não serem suficientes as causas anteriores para explicar a variação denominativa, Freixa (2014) propõe as causas cognitivas, que englobam a imprecisão conceitual, o distanciamento ideológico e as diferentes conceptualizações. A imprecisão conceitual foi apontada pela autora como um subtipo das causas cognitivas pelas muitas maneiras e caminhos possíveis de formação de um conceito; além disso, porque diferenças ideológicas dos especialistas acerca de um assunto podem gerar diferentes formas de denominação, esses nomes são orientados por essas convicções. As diferentes conceptualizações referem-se às diversas maneiras de realização do conhecimento e de acesso a um conceito.

Vale ressaltar que entendemos os textos aqui analisados como gêneros textuais ${ }^{4}$, ou seja, como formas de comunicação estabelecidas e conhecidas que circulam na esfera do Direito. Esses gêneros textuais, como a petição inicial, a contestação, a impugnação e a sentença, entre outros, tornam-se objetos que revelam a materialização do discurso jurídico. Sublinhamos, também, a grande variedade de gêneros (tanto orais quanto escritos) de que dispõe a área jurídica e consideramos que cada um desses gêneros surgiu de uma necessidade comunicativa e se constitui com características e funções que visam a atingir um determinado objetivo entre os participantes de determinado contexto social.

Compartilhando dessa perspectiva de gêneros textuais, entendemos que seria relevante apresentar o que são os textos que analisamos e qual sua função no ramo forense. Isso fazemos porque partimos do pressuposto de que, sendo nossa pesquisa de natureza linguística, não jurídica, dialogamos com leitores que, possivelmente, estejam menos familiarizados com a natureza dos textos forenses e com sua terminologia. Por isso, decidimos arrolar, primeiramente, os conceitos como os de peça e petição, pois podemos considerar que esses são gêneros de natureza ampla, ou seja, o conceito de peça engloba uma

\footnotetext{
${ }^{4}$ Consideramos como gênero textual as formas comunicativas que, no contexto jurídico, são consolidadas. Bakhtin (1997 [1979], p.279) denomina como gêneros discursivos os enunciados "relativamente estáveis" que se formam a partir de necessidades comunicativas distintas. Reconhecemos também as discussões relativas aos gêneros discursivos e gêneros textuais, mas não abordaremos essa temática neste artigo.
} 
quantidade substancial de textos jurídicos de todas as áreas do Direito, como a petição, a sentença etc.

A petição, por sua vez, caracteriza-se como um meio de acessar ao poder judiciário, seja por meio de uma petição inicial, seja por meio de uma contestação etc. Assim sendo, verifica-se que a petição é um tipo de peça, mas que também se DIVIDE EM SUBTIPOS, TAIS COMO A IMPUGNAÇÃO, A CONTESTAÇÃO E A PETIÇÃO INICIAL. DESTACAMOS QUE, INDEPENDENTEMENTE DE SUA NATUREZA, A PETIÇÃO NECESSITA APRESENTAR CARACTERÍSTICAS ESPECÍFICAS PREVISTAS PELO CÓDIGO DE PROCESSO CIVIL (CPC) (BRASIL 2015) para que possa ser validada perante o poder judiciário.

A fim de esclarecer o tipo de material que constitui nosso corpus de análise, buscamos a definição desses gêneros em três dicionários diferentes, isto é, recorremos ao Vocabulário Jurídico, de Silva (2014), a um dicionário padrão de língua Portuguesa (o Aulete Digital) e a um dicionário de gêneros textuais, de Costa (2009).

Quadro 2 - Definições de peça e petição

\begin{tabular}{|c|c|c|}
\hline Aulete Digital & $\begin{array}{l}\text { Vocabulário jurídico, } \\
\text { Silva (2014) }\end{array}$ & $\begin{array}{c}\text { Dicionário de } \\
\text { gêneros textuais } \\
\text { Costa (2009) }\end{array}$ \\
\hline \multicolumn{3}{|l|}{ Peça } \\
\hline $\begin{array}{l}\text { 19. Jur. Documento que } \\
\text { integra um processo. }\end{array}$ & \begin{tabular}{|l}
{$[\ldots]$ Na terminologia } \\
forense, é o documento ou \\
qualquer escrito que se \\
integre ou faça parte dos \\
autos do processo. \\
Designa, pois, qualquer \\
parte elementar ou \\
componente do processo: \\
petição, contestação, \\
laudo, documentos \\
probatórios, depoimento \\
etc. (SILVA 2014: 1023)
\end{tabular} & $\mathrm{N} / \mathrm{C}$ \\
\hline \multicolumn{3}{|l|}{ Petição } \\
\hline $\begin{array}{l}\text { 19. Jur. Documento que } \\
\text { integra um processo. }\end{array}$ & $\begin{array}{|ll|}{[\ldots] \quad \mathrm{Na} \text { terminologia }} \\
\text { forense, é o documento ou } \\
\text { qualquer escrito que se } \\
\text { integre ou faça parte dos } \\
\text { autos do processo. } \\
\text { Designa, pois, qualquer } \\
\end{array}$ & $\begin{array}{l}\text { PETIÇÃO (v. ABAIXO } \\
\text { ASSINADO, INICIAL, } \\
\text { REQUERIMENTO): } \\
\text { formulação escrita de } \\
\text { pedido (v.), dirigida } \\
\text { ao juiz competente }\end{array}$ \\
\hline
\end{tabular}




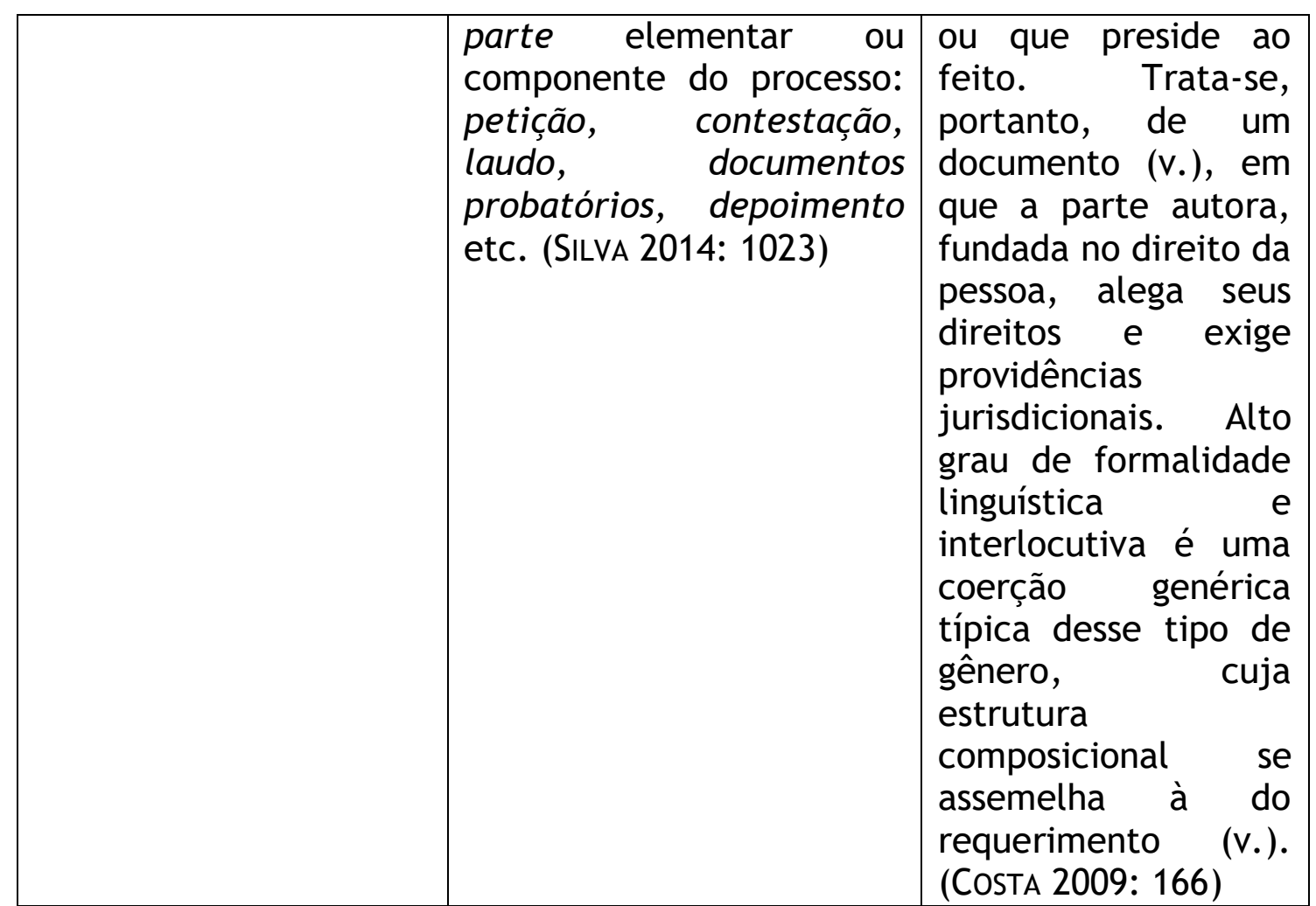

Fonte: Elaboração própria com base em Aulete Digital; Silva (2014) e Costa (2009).

Verificamos que, dos dicionários consultados, o dicionário de Costa (2009) não define o termo peça. Nossa hipótese para tal seria a de que a peça abrange uma ampla quantidade de textos de tipos diversos e, portanto, seria inviável descrevê-la de modo a apontar traços composicionais específicos.

Quadro 3 - Definições dos gêneros textuais estudados no artigo

\begin{tabular}{|c|c|c|}
\hline Aulete Digital & $\begin{array}{l}\text { Vocabulário jurídico, Silva } \\
\text { (2014) }\end{array}$ & $\begin{array}{c}\text { Dicionário de } \\
\text { gêneros textuais } \\
\text { Costa (2009) }\end{array}$ \\
\hline \multicolumn{3}{|l|}{ Impugnação } \\
\hline $\begin{array}{l}\text { 2. Jur. Conjunto } \\
\text { de razões ou } \\
\text { argumentos com } \\
\text { que se impugna. }\end{array}$ & $\begin{array}{l}\text { Do latim impugnatio, de impugnare } \\
\text { (atacar, combater, contradizer), } \\
\text { na prática forense quer exprimir } \\
\text { todo ato de repulsa, de } \\
\text { contestação, de contradita, } \\
\text { praticado contra atos do adversário } \\
\text { ou parte contrária, pelos quais se } \\
\text { procura anular ou desfazer suas } \\
\text { alegações ou pretensões, ou } \\
\text { impedir que promova ato } \\
\text { processual, demonstrado ou } \\
\text { julgado injusto. }\end{array}$ & $\mathrm{N} / \mathrm{C}$ \\
\hline
\end{tabular}




\begin{tabular}{|c|c|c|}
\hline & $\begin{array}{l}\text { [...] } \\
\text { Na prática forense, a impugnação } \\
\text { pode objetivar-se de várias } \\
\text { maneiras. Pode apresentar-se } \\
\text { como contestação, contrariedade, } \\
\text { exceções, como pode ser } \\
\text { considerada sob a modalidade de } \\
\text { recursos, que não passam estes de } \\
\text { impugnações aos despachos ou } \\
\text { decisões proferidas no processo. } \\
\text { (SILVA 2014: 724) }\end{array}$ & \\
\hline \multicolumn{3}{|l|}{ Sentença } \\
\hline $\begin{array}{l}\text { 3. Julgamento ou } \\
\text { decisão final de } \\
\text { qualquer juiz ou } \\
\text { tribunal: } \\
\text { libertado } \\
\text { por sentença. [À } \\
\text { sentença dos } \\
\text { tribunais de } \\
\text { segunda instância } \\
\text { dá-se o nome de } \\
\text { acórdão.] }\end{array}$ & $\begin{array}{l}\text { Do latim sententia (modo de ver, } \\
\text { parecer, decisão), a rigor da } \\
\text { técnica jurídica, e em amplo } \\
\text { conceito, sentença designa a } \\
\text { decisão, a resolução ou a solução } \\
\text { dada por uma autoridade a toda e } \\
\text { qualquer questão submetida à sua } \\
\text { jurisdição. } \\
\text { Assim, toda sentença importa num } \\
\text { julgamento, seja quando implica } \\
\text { uma solução dada à questão } \\
\text { suscitada ou quando se mostra uma } \\
\text { resolução da autoridade que a } \\
\text { profere. } \\
\text { [...] } \\
\text { Na acepção de um julgamento ou } \\
\text { decisão, a sentença, em amplo } \\
\text { sentido, é a pronunciação da } \\
\text { autoridade sobre fato que lhe é } \\
\text { submetido. (SILVA 2014: 1278-1279) }\end{array}$ & $\begin{array}{l}\text { SENTENÇA (v. ADÁGIO, } \\
\text { DITADO, MÁXIMO, } \\
\text { MOTE, PROVÉRBIO): } \\
\text { enunciado, } \\
\text { geralmente, não muito } \\
\text { longo, que encerra um } \\
\text { pensamento de ordem } \\
\text { geral e de valor moral. } \\
\text { Pode ser também uma } \\
\text { decisão, uma resolução } \\
\text { ou uma solução dada } \\
\text { por um júri, uma } \\
\text { autoridade, etc. a toda } \\
\text { e qualquer questão } \\
\text { submetida à sua } \\
\text { jurisdição ou ainda } \\
\text { mesmo uma decisão } \\
\text { inabalável, conceito, } \\
\text { opinião sensata ou } \\
\text { fundamentada, dada } \\
\text { por qualquer pessoa. } \\
\text { (Costa 2009: 185) }\end{array}$ \\
\hline \multicolumn{3}{|l|}{ Contestação } \\
\hline $\begin{array}{l}\text { 4. Jur. Petição em } \\
\text { que o réu contraria } \\
\text { o pedido do autor } \\
\text { da ação. }\end{array}$ & $\begin{array}{l}\text { Derivado do latim contestatio, } \\
\text { de contestari, possui o vocábulo } \\
\text { sentidos bem divergentes: } \\
\text { a) quer significar a atestação, } \\
\text { testemunho, confirmação; } \\
\text { b) quer significar protesto ou } \\
\text { contradita. } \\
\text { No entanto, tendo-se mais em } \\
\text { vista o sentido que lhe empresta } \\
\text { a linguagem forense, a } \\
\text { contestação mais se oferece } \\
\text { como disputa ou contenda, } \\
\text { protesto ou contradita. } \\
\text { [...] modo, a contestação } \\
\text { Desse mo } \\
\text { apresenta-se como a primeira }\end{array}$ & $\mathrm{N} / \mathrm{C}$ \\
\hline
\end{tabular}




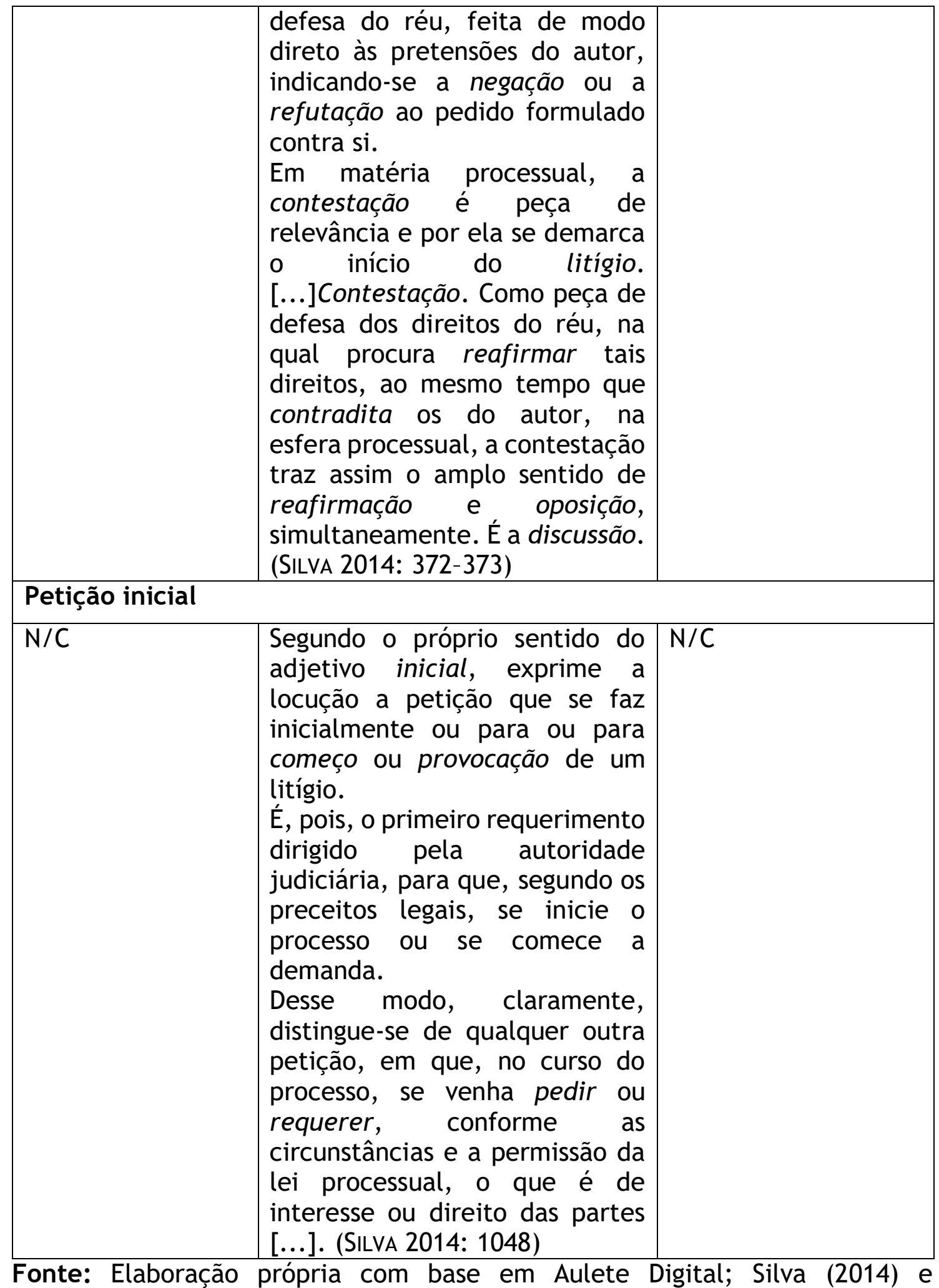

Costa (2009)

\section{Materiais e métodos}


Para a realização desta pesquisa, seguimos alguns procedimentos que julgamos conveniente destacar nesta seção. Andrade (2009 apud FRöHLICH 2014: 191) apresenta em seu trabalho uma lista de unidades terminológicas correspondentes ao termo petição inicial. Dentre os diversos temas abordados pela autora que citamos, está o juridiquês, ou seja, a linguagem característica do Direito. A unidade léxica juridiquês foi criada para designar a língua em uso no âmbito da especialidade jurídica. 0 juridiquês mostra-se tão complexo que parece desdobrar-se em um idioma diferente do português. Por isso, juridiquês faz referência à complexidade atribuída à língua em uso no Direito. A lista disponibilizada por Andrade (2009 apud FRöHLICH 2014) é a seguinte:

Quadro 4 - Lista de possíveis variantes do termo petição inicial

\begin{tabular}{|l|l|l|}
\hline peça atrial & peça inaugural & peça primígena \\
peça autoral & peça incoativa & peça prodrômica \\
peça de arranque & peça introdutória & peça proemial \\
peça de ingresso & peça ovo & peça prologal \\
peça de intróito & peça preambular & peça pórtico \\
peça dilucular & peça prefacial & peça umbilical \\
peça exordial & peça preludial & peça vestibular \\
peça gênese & peça primeva & \\
\hline
\end{tabular}

Fonte: Elaboração própria com base em Andrade (2009 apud FRÖHLICH 2014: 191)

Além dos termos do quadro 4 e do próprio termo petição inicial, acrescentamos mais nove possíveis denominações coocorrentes ${ }^{5}$ para se referir ao mesmo conceito, que são: exordial, inicial, peça inicial, pedido inicial, peça prologal, peça introito, increpatória, peça preliminar, incoativa. No total, somam-se, então, 34 termos sinônimos que buscamos no corpus.

Em face do exposto, seguindo uma perspectiva mais comunicativa acerca da Terminologia, decidimos investigar a variação denominativa para o termo petição inicial. Para tanto, montamos um corpus de análise com o auxílio de um operador do Direito, com acesso ao banco de dados da OAB (Ordem dos Advogados do Brasil), que nos forneceu nove sentenças, três impugnações e oito

\footnotetext{
${ }^{5}$ Tomamos emprestado o termo coocorrentes de Faulstich (1995), mas não aplicamos seus conceitos teóricos neste trabalho.
} 
contestações para que pudéssemos verificar a existência de variação denominativa nesses textos e o modo como ela ocorre. Justificamos a escolha dos gêneros textuais citados pelo motivo de não serem peças forenses introdutórias nos processos judiciais. Em outras palavras, as sentenças, as contestações e as impugnações são elaboradas posteriormente à petição inicial; logo, entendemos que há maior probabilidade de se recuperar ou mencionar o termo petição inicial ou suas variantes nos gêneros textuais que selecionamos.

Feito esse levantamento dos textos, coube-nos identificar se havia uso de algum dos termos discriminados como sinônimos de petição inicial por Andrade (2009 apud FRÖHLICH 2014). Realizamos uma busca dos 23 termos considerados sinônimos de petição inicial no corpus, mais 11 possíveis variantes, totalizando 34. Tal tarefa se deu com o auxílio do mecanismo de busca "Pesquisa avançada" (Shift $+\mathrm{C} t r \mathrm{~L}+\mathrm{L}$ ) disponível no software de textos Adobe Reader.

Identificadas as ocorrências dos termos, desenvolvemos a análise dos contextos nos quais ocorrem os diferentes usos para o termo petição inicial.

\section{Análises}

Nesta seção, dedicamo-nos a apresentar as análises realizadas no corpus. Como citamos, foram analisados 20 textos, incluindo sentenças, impugnações e contestações. Buscamos o uso de 34 termos consideradas como possíveis variantes do termo petição inicial. Elaboramos um quadro com a finalidade de demonstrar os termos encontrados nos textos e suas respectivas frequências.

Quadro 5 - Termos e frequência de ocorrência no corpus

\begin{tabular}{|c|c|c|c|c|c|c|}
\hline Termo & Inicial & $\begin{array}{c}\text { Peça } \\
\text { inicial }\end{array}$ & $\begin{array}{c}\text { Petição } \\
\text { inicial }\end{array}$ & Exordial & $\begin{array}{c}\text { Peça } \\
\text { vestibular }\end{array}$ & $\begin{array}{c}\text { Pedido } \\
\text { inicial }\end{array}$ \\
\hline Quantidade & 66 & 2 & 11 & 10 & 1 & 5 \\
\hline
\end{tabular}

Fonte: Elaboração própria 
Com base no quadro 5, elaboramos o gráfico 1 , a seguir, o qual mostra a porcentagem de ocorrências no corpus analisado das variantes denominativas para o conceito de texto inicial de um processo, também denominado como petição inicial. Verifica-se que a variante inicial constitui-se como o termo mais frequente, contabilizando $69 \%$ das ocorrências.

Gráfico 1 - Porcentagem de termos no corpus

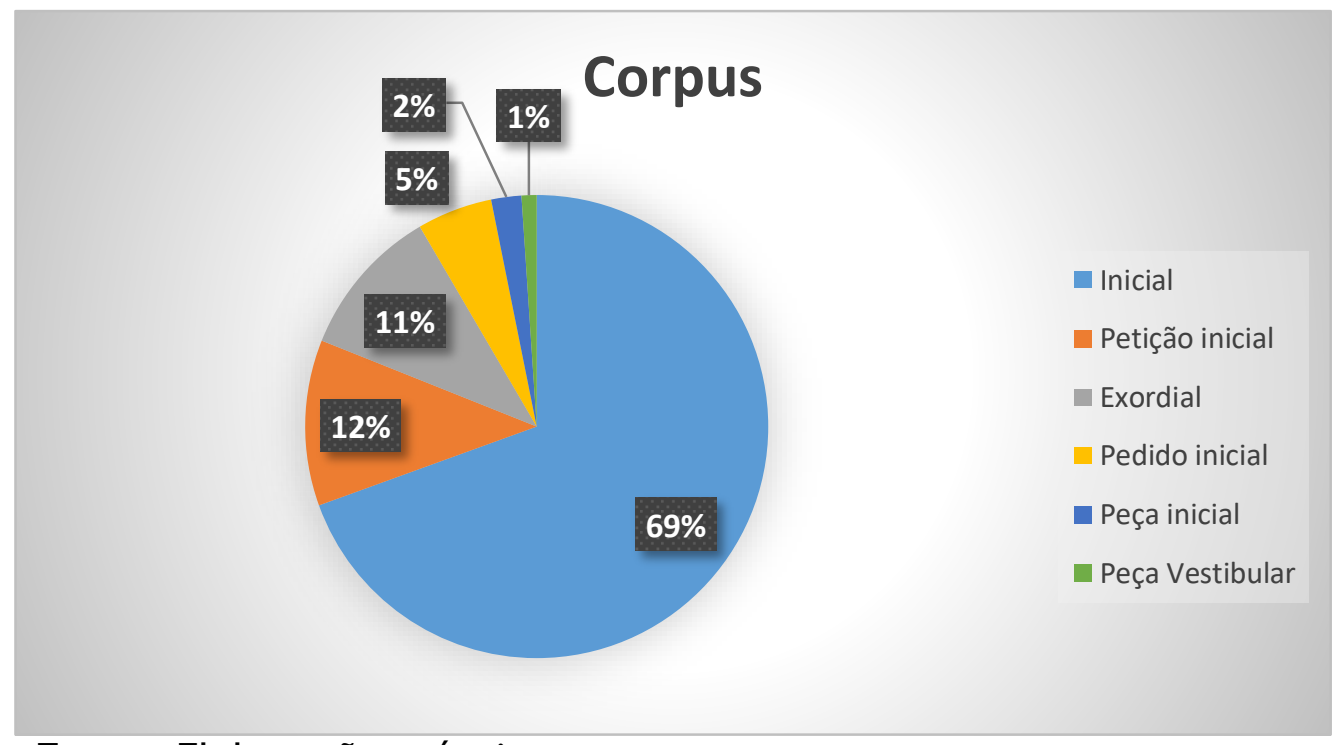

Fonte: Elaboração própria

Concentramo-nos nas variantes denominativas que coocorrem no corpus e que designam o conceito de petição inicial. Ao observarmos o quadro 2 e o gráfico 1 , notamos que há seis possíveis sinônimos referentes a esse conceito: inicial, petição inicial, exordial, pedido inicial, peça inicial e peça vestibular. Selecionamos alguns contextos a fim de identificar e analisar as possíveis causas. Em um único texto, encontramos três usos diferentes, a saber: peça vestibular, petição inicial e exordial. Recortamos os contextos para analisar como as diferentes expressões são apresentadas.

TEXTO 1 - Ocorrências:

\section{Peça vestibular:}

[...] Além da absurda dimensão que a peça vestibular pretende emprestar [...] 
Petição inicial:

[...]SíNTESE DA PETIÇÃO INICIAL [...]

Inicial:

[...] verossimilhança das alegações tecidas na inicial [...]

Exordial:

[...] evento narrado na exordial [...]

TEXTO 2- Ocorrências

Pedido inicial:

[...] alterou seu pedido inicial.

Petição inicial:

[...] deferir a petição inicial [...]

Inicial:

[...] dos pedidos da inicial [...]

[...] pagamento dos pedidos da inicial [...]

TEXTO 3 - Ocorrências

Petição inicial:

[...] INÉPCIA DA PETIÇÃO INICIAL [...]

[...] indeferir a petição inicial [...]

Inicial:

[...] Através da inicial [...]

$[\ldots]$ a mesma reconheceu expressamente na inicial $[\ldots]$

Por meio dos exemplos arrolados, é possível confirmar que a variação maior ocorre entre os termos petição inicial, inicial e exordial. Entendemos, a partir dos excertos, que ocorre a variação denominativa. Dentre as amostras que apresentamos, a alternância entre as três variantes ocorre no mesmo texto, isto é, elas denominam o mesmo conceito. Inclusive, tal variação ocorre em função do fato de que a contestação, a impugnação e a sentença são réplicas aos textos iniciais do processo, ou seja, são gêneros textuais que respondem às petições iniciais. 
A priori, atribuímos a variação às causas discursivas e seus três subtipos (evitar a repetição, economia linguística e criatividade, ênfase $e$ expressividade) como as principais razões para a alternância no uso dos termos verificados como sinônimos de petição inicial. Nos exemplos encontrados no texto 1 (exemplos acima citados), em que há uso de quatro termos diferentes, peça vestibular, petição inicial, inicial e exordial, entendemos que o autor recorre a essa alternância a fim de evitar repetições e em função da expressividade. A expressividade torna-se uma causa de variação na medida em que o texto 1 foi elaborado por três profissionais diferentes, cada um com experiências e formações distintas.

As segundas causas são a economia linguística e evitar repetição, as quais ocorrem concomitantemente. Nos textos 2 e 3, identificamos o uso de petição inicial, pedido inicial e inicial. Em ambos os textos analisados, petição inicial e inicial são encontrados espacialmente próximos, o que, possivelmente, suscita o emprego de unidades terminológicas diferentes, ou seja, a alternância entre as variantes pode ser uma estratégia textual anafórica utilizada para tornar o texto menos repetitivo ou mais sucinto.

Com relação à causa economia linguística, causa apontada por Freixa (2014), verificamos que o uso de unidades terminológicas sintagmáticas como petição inicial ou pedido inicial e mais adiante apenas inicial podem demonstrar um movimento natural da língua, que é o caminho da redução, da economia. Portanto, entende-se que, com o uso de petição inicial e de apenas inicial, a comunicação não fica comprometida; pois são termos que se alternam em função da economia linguística.

\section{Considerações Finais}

Nossa pesquisa foi motivada pela constatação de possíveis variantes para o termo petição inicial em textos do Direito. Nosso objetivo, portanto, foi verificar se os possíveis nomes alternativos para petição inicial ocorriam nos textos, de que forma essas variantes estavam apresentadas e as possíveis razões para tal. Analisamos 20 exemplos de textos, que compõem o corpus, e que 
podem ser categorizados como contestações, impedimentos e sentenças. Esses textos são elaborados em resposta à petição inicial; logo, são posteriores a ela e entendemos que, nesses gêneros, há maior probabilidade de se fazer referência ao documento que deu início ao processo jurídico.

Feita a seleção dos textos, realizamos uma busca pelos termos que havíamos recortado como possíveis variantes de petição inicial e analisamos os dados com base nos fundamentos teóricos arrolados. Dentre esses, pautamonos na Teoria Comunicativa da Terminologia, de Cabré (1999), e em Freixa (2002, 2014) acerca da variação terminológica. Para Freixa (2014), a variação terminológica é um fenômeno intrínseco à língua. Ela sempre ocorre em função de alguma motivação dos participantes na comunicação. Partilhamos da ideia de que há sempre razão para que a variação aconteça.

Notamos que, dentre os 34 termos buscados nos textos como candidatos a variantes denominativas de petição inicial, apenas seis foram encontrados nos textos analisados. Consideramos que esse fato possa estar associado a alguns fatores. 0 primeiro seria que as peças que analisamos são mais atuais e que alguns dos termos analisados como possíveis variantes são considerados em desuso ou mais antigos como, por exemplo, peça ovo, peça de intróito ou dilucular. 0 outro fator refere-se ao fato de que, ainda que tenhamos estabelecido uma metodologia para escolher textos subsequentes à petição inicial em um processo, são poucas as referências feitas pelos operadores de Direito à peça inicial do processo. Tal fato inibe a produtividade desse termo nos textos.

Por último, notamos que há uma modificação na linguagem jurídica que tende a se transformar com o passar dos anos e com o ingresso de novos profissionais que têm em sua formação contato com iniciativas de aproximação entre a linguagem jurídica e o cidadão comum.

Entendemos que, ainda que a variação seja um acontecimento natural da língua, o fato de termos encontrado, no corpus que analisamos, poucos exemplos da lista que apresentamos (quadro 4) sinaliza modificações no cenário terminológico do Direito, em que alguns profissionais tendem a dispensar termos como peça de intróito ou dilucular, que são menos frequentes ou 
desusadas, e dar lugar a peça inicial ou peça exordial, alternando apenas entre um e outro.

Consideramos que nosso trabalho fez um pequeno recorte de gêneros e de textos analisados. Julgamos que, à medida que ampliássemos nosso corpus de pesquisa e buscássemos textos produzidos em diferentes épocas, possivelmente encontraríamos mais usos dos exemplos da lista de possíveis denominações para o conceito petição inicial e, talvez, mais unidades terminológicas em desuso atualmente-

\section{Referências}

AULETE, C. Aulete Digital. Dicionário contemporâneo da língua portuguesa: Dicionário Caldas Aulete, online. Lexikon Editora digital. Disponível em: <http://www.aulete.com.br/>. Acesso em: 14 out. 2017.

BAKHTIN, M. M. Estética da criação verbal. São Paulo: Martins Fontes, 1997 [1979].

Barros, L. A. Curso básico de terminologia. São Paulo: Edusp, 2004.

BRASIL. Lei no 13.105, de 16 de março de 2015. Código de Processo Civil. Diário Oficial da União, Brasília, 2015. Disponível em:

<http://www.planalto.gov.br/ccivil_03/_ato2015-

2018/2015/lei//13105.htm>. Acesso em: 06 dez. 2019.

CABRÉ, M. T. La Terminologia: Representación y comunicación: Elementos para uma teoria de base comunicativa y otros artículos. Barcelona: Institut Universitari de Linguística aplicada, 1999.

CostA, S. R. Dicionário de gêneros textuais. 2.ed. rev. ampl. Belo Horizonte: Autêntica Editora, 2009.

FAULSTICH, E. Socioterminologia: mais que um método de pesquisa, uma disciplina. Ciência da Informação, v. 24, n. 3, Brasília, DF, 1995. Disponível em:

<http://www.brapci.inf.br/_repositorio/2010/03/pdf_bb636decd3_0008870.p df $>$. Acesso em: 19 jun. 2017.

FREIXA, J. Causes of denominative variation in terminology: A typology proposal. Terminology, v. 12, Amsterdam/Philadelphia: J Benjamins, 2006. 
. La variació terminològica. Anàlisi de la variació denominativa en textos de diferent grau d'especialització de l'àrea de medi ambient. 2002, 397f. Tese (Variació en el Llenguatge) - Universidade de Barcelona:

Barcelona, 2002.

La variación denominativa em Terminologia: Tipos y causas. In:

IsQUeRDo, A. N.; DAL CoRno, G. O. M. (Org.). As ciências do léxico: lexicologia, lexicografia, terminologia. v. 07. Campo Grande: Editora UFMS, 2014, p. 305323.

FRÖHLICH, L. R. Tradução Forense: Um Estudo de Cartas Rogatórias e suas Implicações. 347 f. Tese (Tese de Doutorado em Estudos da Tradução) Universidade Federal de Santa Catarina, Florianópolis, 2014. Disponível em: <http://www.pget.ufsc.br/curso/teses/Luciane_Reiter_Frohlich_-_Tese.pdf>. Acesso em: 08 ago. 2019.

HoffMANn, L. Llengatges d'especialitat. Barcelona: Institut Universitari de Lingüística Aplicada, Universitat Pompeu Fabra, 1998.

Isquerdo, A. N.; Dal CoRno, G. O. M. (Org.). As ciências do léxico: lexicologia, lexicografia, terminologia. v. 07. Campo Grande: Editora UFMS, 2014.

MURAKAWA, C. A. A.; NADIN, O. L. Terminologia: uma ciência interdisciplinar. São Paulo: Cultura Acadêmica, 2013.

NADIN, O. L. A variação denominativa em terminologia: A problemática das siglas. In: MURAKAWA, C. A. A.; NADIN, O. L. Terminologia: uma ciência interdisciplinar. São Paulo: Cultura Acadêmica, 2013, p. 167-185.

Pereira, A. H. Terminologia do Direito do Consumidor: Análise das motivações da variação terminológica. $108 \mathrm{f}$. Dissertação (mestrado em Linguística e Língua Portuguesa) - Faculdade de Ciências e Letras, Universidade Estadual Paulista. Araraquara, 2018.

SILVA, De P. e. Vocabulário Jurídico, atualizadores: Nagib Slaibi Filho e Priscila Pereira Vasques Gomes. 31. ed. Rio de Janeiro: Forense, 2014.

Recebido em: 07/08/2019

Aceito em: 21/11/2019

Publicado em dezembro de 2019 